\title{
Engaging Primary Care Patients to Use a Patient- Centered Personal Health Record
}

Alex H. Krist, MD, MPH ${ }^{1,2}$

Steven H. Woolf, MD, MPH $H^{1,3}$

Gbalib A. Bello, BS

Roy T. Sabo, $P b D^{1,4}$

Daniel R. Longo, ScD ${ }^{1}$

Paulette Kasbiri, MPH ${ }^{1}$

Rebecca S. Etz, PbD ${ }^{1}$

Jobn Loomis, BS

Stephen F. Rothemich, $M D, M S^{1}$

J. Eric Peele, $B A^{5}$

Jeffrey Cobn, $M D^{6}$

'Department of Family Medicine and

Population Health, Virginia Commonwealth

University, Richmond, Virginia

${ }^{2}$ Fairfax Family Practice Residency, Fairfax,

Virginia

${ }^{3}$ Center on Society and Health, Virginia

Commonwealth University, Richmond,

Virginia

${ }^{4}$ Department of Biostatistics, Virginia Commonwealth University, Richmond, Virginia

${ }^{5}$ RTI International, Research Triangle Park, North Carolina

${ }^{6}$ Broadlands Family Medicine, Ashburn, Virginia

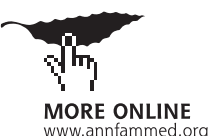

Conflicts of interest: Virginia Commonwealth University bolds the intellectual property rights to the interactive preventive bealth record evaluated in this study. Although the university and developers are entitled to the system's revenue, the tested interactive preventive bealth record (MyPreventiveCare) is a noncommercial product, and no revenues have been generated other than grant funding.

\section{CORRESPONDING AUTHOR}

Alex H. Krist MD, MPH

PO Box 980251

Richmond VA 23298-0251

ahkrist@vcu.edu

\begin{abstract}
PURPOSE Health care leaders encourage clinicians to offer portals that enable patients to access personal health records, but implementation has been a challenge. Although large integrated health systems have promoted use through costly advertising campaigns, other implementation methods are needed for small to medium-sized practices where most patients receive their care.
\end{abstract}

METHODS We conducted a mixed methods assessment of a proactive implementation strategy for a patient portal (an interactive preventive health record [IPHR]) offered by 8 primary care practices. The practices implemented a series of learning collaboratives with practice champions and redesigned workflow to integrate portal use into care. Practice implementation strategies, portal use, and factors influencing use were assessed prospectively.

RESULTS A proactive and customized implementation strategy designed by practices resulted in $25.6 \%$ of patients using the IPHR, with the rate increasing $1.0 \%$ per month over 31 months. Fully $23.5 \%$ of IPHR users signed up within 1 day of their office visit. Older patients and patients with comorbidities were more likely to use the IPHR, but blacks and Hispanics were less likely. Older age diminished as a factor after adjusting for comorbidities. Implementation by practice varied considerably (from $22.1 \%$ to $27.9 \%, P<.001$ ) based on clinician characteristics and workflow innovations adopted by practices to enhance uptake.

CONCLUSIONS By directly engaging patients to use a portal and supporting practices to integrate use into care, primary care practices can match or potentially surpass the usage rates achieved by large health systems.

Ann Fam Med 2014;12:418-426. doi: 10.1370/afm.1691.

\section{INTRODUCTION}

$\square$ lectronic personal health records hold great promise for improving health. High-quality personal health records can facilitate connectivity between patients and clinicians, allow patients to view their medical record, support online clinical and administrative transactions, deliver essential resources to promote informed decision making, and more actively engage patients in care. ${ }^{1}$

In the United States, regulations developed by the Office of the National Coordinator and the Centers for Medicare and Medicaid Services to strengthen the functionality of electronic health record systems (meaningful use regulations) encourage practices to engage patients in care through information technology, such as personal health records. ${ }^{2,3}$ Although patients appear interested ${ }^{4,5}$ practices cannot meet this need without infrastructure, workflow, and cultural changes. Most published experiences with engaging patients online have occurred in integrated health systems that have resources and business models to support adoption, implementation, and maintenance of the personal health record. ${ }^{6-9}$ For example, between 2002 and 2009, Kaiser Permanente and Group Health Cooperative of Puget Sound made major investments to promote online services, resulting in uptake by $27 \%$ and $58 \%$ of patients, respectively, over 6 to 9 years. ${ }^{6,7}$ 
Little is known about whether small to mediumsized practices (eg, 15 or fewer clinicians) — where most primary care services are provided — can replicate these successes or how their experiences will differ. Even less is known about which patients will use and derive benefits from a personal health record. Some skeptics worry that focusing on information technology could exacerbate health disparities related to raceethnicity, age, or socioeconomic status. ${ }^{10}$

Patients can be meaningfully engaged in their care through personal health records that are patientcentered, interactive, relevant, and integrated into care. ${ }^{11,12}$ In our prior work, we described a model to make personal health records more patient centered, ${ }^{11}$ created a patient-centered personal health record for prevention (termed an interactive preventive health record, IPHR,$_{1}^{13}$ and demonstrated in a randomized controlled trial that offering the IPHR to patients increased delivery of evidence-based preventive services. ${ }^{14,15}$ Uptake of the IPHR, however, relied on mailing patients an invitation to use the portal, and only $16.8 \%$ of invited patients responded.

To improve uptake, we hypothesized that practices could more effectively promote IPHR use by making it part of patient care and using approaches and workflows customized by practices. This manner of promotion would be more applicable to primary care than methods used by large integrated health systems. We extended our original study ${ }^{14}$ at 8 practices to test this hypothesis in a large sample of patients exposed to the IPHR.

\section{METHODS}

Between December 2010 and June 2013, we applied a mixed methods design to prospectively evaluate the feasibility of whether small to medium-sized primary care practices could engage patients to use the IPHR We observed whether patients and clinicians used the IPHR and factors associated with use. The Virginia Commonwealth University Institutional Review Board approved this study (\#HM12746).

\section{Setting}

The study was conducted at 8 practices in the Virginia Ambulatory Care Outcomes Research Network (ACORN) that participated in the previously reported IPHR efficacy trial. The practices are located within a 35 -mile radius, spanning 5 northern Virginia counties. They operate independently for clinical, staffing, and business activities, but use a common electronic health record (EHR) (AllscriptsTouchworks EHR, Allscripts) and a commercial portal that only provides secure patient messaging.

\section{Intervention}

In 2009, the 8 practices agreed to offer the IPHR to all patients aged 18 to 75 years. Although we attempted to integrate the IPHR into the practices' secure messaging portal, the vendor was not able to support integration. Accordingly, practices had to field 2 portals concurrently.

The IPHR provides personally tailored recommendations and resources for 18 preventive services recommended by the US Preventive Services Task Force (USPSTF) and associated chronic conditions. ${ }^{16}$ The IPHR design is published elsewhere. ${ }^{13,15,17}$ In brief, patients who visit the IPHR create an account that links the system to their clinician's EHR. The IPHR extracts hundreds of EHR data elements, and patients complete a health risk assessment of patient-reported information (eg, health behaviors) and information poorly recorded in EHRs (eg, family history, surgical history).

Based on the USPSTF and 6 other guidelines, ${ }^{16,19-25}$ the IPHR applies programmed logic to generate a personally tailored list of preventive and chronic care recommendations with 392 variations of patient educational material. The site provides detailed personal messages that explain each service and its rationale, references relevant elements of the patient's history, includes links to evidence-based educational materials and decision aids, and summarizes next steps. After patient use, the IPHR forwards a summary to the EHR inbox of the patient's clinician. Initially, the IPHR provided only laboratory results for selected screening tests. In month 10, IPHR functionality was upgraded to enable patients to view all laboratory results, with an explanatory message from their clinician.

Study practices received no financial incentives, although the IPHR was provided at no cost. Using organizational change theory as a guide ${ }^{26-32}$ we provided practices basic implementation assistance. Two champions from each practice participated in 7 learning collaboratives to share implementation experiences, train practice clinicians and staff to use the IPHR, and direct local implementation strategies. Other research team support included conducting learning collaboratives (led by A.H.K. and P.K.) and providing weekly IPHR use feedback. Remaining implementation efforts were practice-driven.

\section{Data Collection}

We used 5 quantitative and qualitative sources for outcomes: EHR data, IPHR data, learning collaborative transcripts, a clinician survey, and exit interviews. From the EHR, we identified all patients seen for an office visit, their demographic characteristics, and their comorbidities. We used the IPHR to identify patients who created an account. Learning collab- 
oratives, which generated qualitative data on how practices implemented the IPHR, were recorded, transcribed, and coded. Practice champions were interviewed after study completion to critique our interpretation of findings.

The clinician survey included questions from the Agency for Healthcare Research and Quality Health IT Survey Compendium. ${ }^{33}$ Questions based on the Technology Acceptance Mode ${ }^{34}$ and diffusion of innovation theory ${ }^{35}$ asked clinicians to rank agreement/disagreement on a 5 -point scale with the following statements: "my office is innovative," "I am comfortable using my EHR," "...I am usually one of the first to find out about a new test or treatment (early adopter)," "promoting prevention is important to our office," "our office has a good system to promote prevention," "training I received about [the IPHR] was adequate," and "I am confident in my ability to use [the IPHR]." ${ }^{136,37}$ Clinicians were e-mailed an invitation to take the survey online 1 year after IPHR implementation. Nonresponders received 3 reminders.

\section{Statistical Analysis}

IPHR use was computed as the percentage of patients aged 18 to 75 years with an office visit during a given month who created an account within 30 days. We calculated overall use and use by practice and clinician for the complete study period and each individual month. Simple linear regression was used to estimate monthly change in use. To compare IPHR use between practices, we used a univariate logistic regression model. Whether patients created an IPHR account was modeled against the practice, which we treated as a categorical explanatory variable.

Using demographic information recorded in the EHR, we compared characteristics of patients who used and did not use the IPHR. For continuous characteristics (eg, age), mean values for users and nonusers were compared using independent 2 -sample $t$ tests. For categorical characteristics (eg, ethnicity and race), percentages of users and nonusers were compared using a univariate logistic regression model.

We conducted a bivariate and multivariate analysis. The bivariate analysis compared whether practices or clinicians had a greater effect on IPHR use. We used a generalized linear mixed model, which had no fixed effects and included the practice and clinician as random effects with a variance components correlation structure. $P$ values were obtained using the COVTEST option of the GLIMMIX procedure, SAS 9.3 (SAS Institute). We conducted a multivariate analysis by applying a generalized linear mixed model to all available clinician covariates (all responses to the clinician survey) and all patient covariates available in the EHR (age, sex, race-ethnicity, and comorbidities) that had a plausible likelihood of affecting IPHR use. We treated the patient and clinician factors as fixed effects and the practice as the sole random effect.

\section{Qualitative Analysis of Learning Collaborative Transcripts}

Using an open-template approach ${ }^{38} 4$ reviewers

(D.R.L., P.K., A.H.K., S.F.R.) used directed coding to capture practice-identified IPHR implementation facilitators, barriers, and workflow impacts.

Two reviewers coded each transcript independently. Merged data were reviewed for discrepancies and discussed by the group to identify themes until reaching consensus. The strength of a given theme was demonstrated by majority participant agreement, consistency of expression, and frequency of associated coding instances.

\section{RESULTS \\ IPHR Use}

During the study period, 112,893 patients aged 18 to 75 years had an office visit, and 28,910 (25.6\%) created an IPHR account. Monthly IPHR use across all 8 practices is shown in Figure 1. The monthly increase in IPHR users was nearly linear, with an estimated monthly increase of $1.0 \%$ ( $\mathrm{SE}=0.03 \%, P<.001)$. Of patients who visited practices in the final month, $32.5 \%$ had a new or preexisting IPHR account. This percentage was a significantly greater uptake $(P<.001)$ than the $16.8 \%$ uptake we observed in our prior efficacy trial, in which the IPHR was promoted only through mailings (Table 1).

Although patients created an IPHR account in an average of 59.5 days after their office visit, $23.5 \%$ of patients did so within 1 day, and thus the median was only 6.0 days. Fully $64.0 \%$ of patients created an IPHR account after 2 office visits, and another $21.8 \%$ did after 4 (median $=2.6$ ) visits. Patients logged into the IPHR an average of 3.7 times after creating an account (range of 1 to 261 times) and spent 7 minutes per session. Among users, $26.7 \%$ visited the site only once.

\section{Factors Influencing Use}

Across the 8 practices there was an initial upsurge in new account creation, a plateau during the middle of the study, and then a decline as more patients seen had an existing account (Figure 2). A group of "high achiever" practices had early increases in new accounts (practices 1 and 8), another group had a more modest delayed surge in uptake (practices 5 and 7 ), and a third group maintained stable but lower usage rates (practices 2, 4, and 6). 
Figure 1. Percentage of patients with an office visit who had established an IPHR account, by month, all 8 practices.

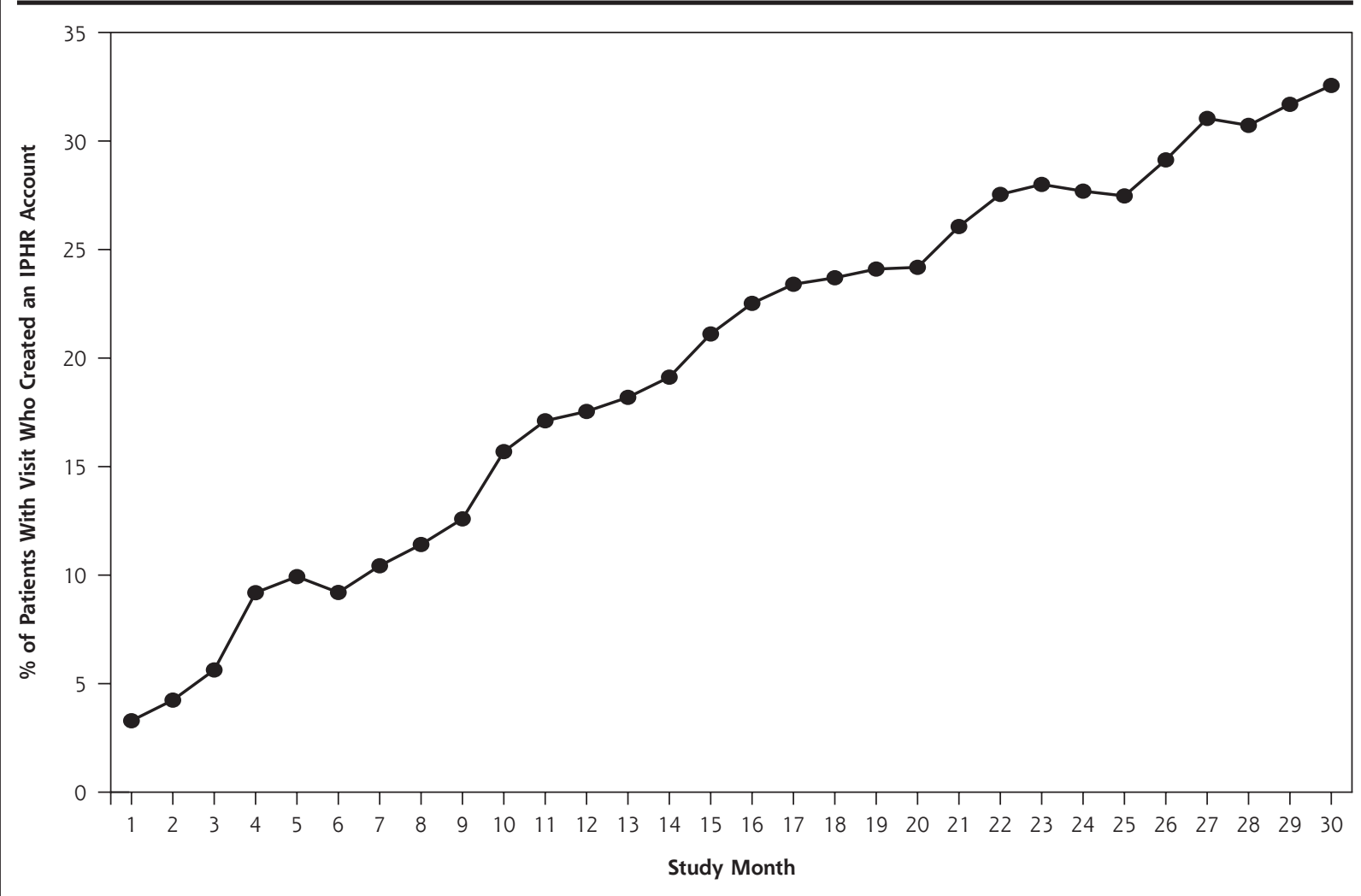

IHPR = interactive preventive health record.

Note: Figure 1 depicts the percentage of patients seen for an office visit in the study practices each month who created an IPHR account within 1 month of their office visit. The study period includes 31 months between December 2010 and June 2013.

Uptake by practice ranged from $22.1 \%$ to $27.9 \%$ (Table 1 ), and use by clinician ranged from $0.0 \%$ to $51.3 \%$. In the bivariate analysis, variance between practices lost significance (variance $=0.00$; $P=.368$ ), whereas the variation between clinicians remained significant (variance $\left.=0.28_{i}, P<.001\right)$.

Operational changes at certain practices may explain individual variation in usage rates across practices. Although the learning collaboratives discussed a range of passive (eg, websites, telephone hold messages, kiosks) and active (eg, distributing cards, brochures) implementation strategies (Supplemental Appendix), certain innovations adopted by practices may account for the marked increases observed in Figure 2.

For example, the first inflection point in month 2 occurred when 2 practices adopted a team approach to engage staff
Table 1. Comparison of IPHR Use With Mailed Invitation (Prior Efficacy Trial) vs Practice-Level Customized Implementation Strategy (Current Study)

\begin{tabular}{lcccc}
\hline & $\begin{array}{c}\text { Mailed Invitation, } \\
\text { 18 months, Prior Trial }\end{array}$ & \multicolumn{2}{c}{$\begin{array}{c}\text { Integrated into Care, } \\
\text { Months, Current Study }\end{array}$} \\
\cline { 2 - 5 } Practice & $\begin{array}{c}\text { Patients } \\
\text { Mailed } \\
\text { Invitation }\end{array}$ & $\begin{array}{c}\text { Pho Created } \\
\text { WhHR Account } \\
\text { No. (\%) }\end{array}$ & $\begin{array}{c}\text { Patients } \\
\text { Patients With } \\
\text { Office Visit }\end{array}$ & $\begin{array}{c}\text { Who Created } \\
\text { IPHR Account } \\
\text { No. (\%) }\end{array}$ \\
\hline 1 & 550 & $69(12.6)$ & 26,659 & $6,668(25.0)$ \\
2 & 50 & $4(8.0)$ & 5,418 & $1,254(23.2)$ \\
3 & 504 & $75(14.9)$ & 23,712 & $6,336(26.7)$ \\
4 & 46 & $5(10.9)$ & 5,181 & $1,205(23.3)$ \\
5 & 500 & $35(7.0)$ & 11,546 & $3,225(27.9)$ \\
6 & 100 & $7(7.0)$ & 6,742 & $1,493(22.1)$ \\
7 & 500 & $70(14.0)$ & 12,697 & $3,218(25.3$ \\
8 & 500 & $77(15.4)$ & 20,938 & $5,511(26.3)$ \\
Total & 2,750 & $342(12.4)$ & 112,893 & $28,910(25.6)$ \\
\hline IPHR = interactive prevention health record. & & \\
Note: A total of 3 invitations to use the IPHR were mailed to a randomly selected sample of 2,750 \\
patients and IPHR use was prospectively tracked for 18 months.
\end{tabular}


Figure 2. IPHR usage rate by practice during the study period.

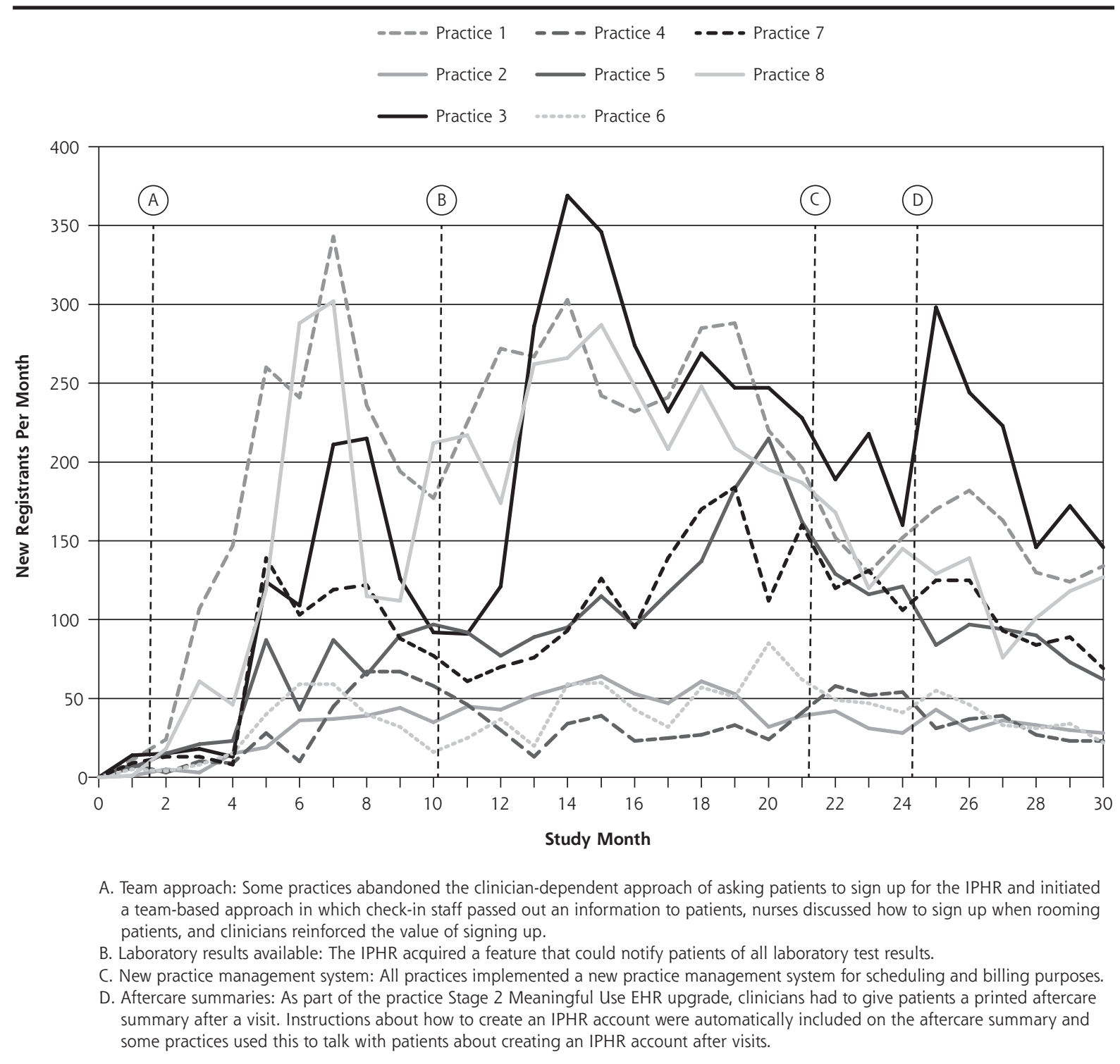

EHR = electronic health record; IPHR = interactive prevention health record.

Note: Variations in how, when, and the degree to which practices implemented these different functionalities and workflows, as well as individual practice contextual factors, are detailed in the Supplemental Appendix.

in notifying patients about the IPHR rather than relying solely on clinicians. Practice 8 created this new workflow: front desk staff stapled information cards to registration sheets and explained the IPHR, nurses discussed the IPHR and reviewed sign-up instructions when rooming patients, and clinicians reinforced the IPHR's value. Practice 1 immediately copied the workflow, and the 2 practices competed to enroll more patients.

The second change occurred in month 10 , when the ability to view all laboratory results became available. Practices 1, 3, and 8 initially utilized this feature, followed by practices 5 and 7 , whereas other practices
$(2,4$, and 6$)$ made less use of this feature. In month 21 , many practices experienced decreases in new registrants when they refocused implementation efforts on adopting a new practice management billing system. Finally, in month 23, practices began generating aftercare summaries for patients to comply with meaningful use requirements. ${ }^{39}$ Practices 1 and 3 adopted an automated program to include information about the IPHR in the aftercare summary, although this routine dissipated after a few months.

In general, IPHR uptake was lower among smaller practices and practices that relied primarily on clini- 
Table 2. Patients Who Created An IPHR Account, by Demographic Characteristics

\begin{tabular}{|c|c|c|c|}
\hline Characteristic & $\begin{array}{c}\text { Study Patients } \\
(\mathrm{N}=112,893) \\
\text { No. }\end{array}$ & $\begin{array}{c}\text { Users } \\
(\mathrm{n}=28,910) \\
\text { No. }(\%)\end{array}$ & $\begin{array}{c}\text { Nonusers } \\
(n=83,983) \\
\text { No. }(\%)\end{array}$ \\
\hline Total number of patients & 112,893 & 28,910 & 83,983 \\
\hline Age, mean, y & $\ldots$ & 45.4 & 41.9 \\
\hline \multicolumn{4}{|l|}{ Use by age } \\
\hline $18-39$ y & 49,162 & $10,185(20.7)$ & $38,977(79.3)$ \\
\hline $40-49 y$ & 27,110 & $7,271(26.8)$ & $19,839(73.2)$ \\
\hline $50-59$ y & 22,261 & $6,841(30.7)$ & $15,420(69.3)$ \\
\hline $60-69 y^{a}$ & 11,542 & $3,802(32.9)$ & $7,740(67.1)$ \\
\hline$\geq 70$ y & 2,818 & $811(28.8)$ & $2,007(71.2)$ \\
\hline \multicolumn{4}{|l|}{ Use by sex } \\
\hline Male & 50,836 & $12,806(25.2)$ & $38,030(74.8)$ \\
\hline Female & 62,039 & $16,102(25.95)$ & $45,937(74.05)$ \\
\hline \multicolumn{4}{|l|}{ Use by comorbidity } \\
\hline None & 68,190 & $14,388(21.1)$ & $53,802(78.9)$ \\
\hline Any & 44,703 & $14,522(32.5)$ & $30,181(67.5$ \\
\hline Diabetes & 6,702 & $2,147(32.0)$ & $4,555(68.0)$ \\
\hline Cancer & 2,483 & $810(32.6)$ & $1,673(67.4)$ \\
\hline Coronary artery disease & 1,830 & $548(29.95)$ & $1,282(70.05)$ \\
\hline Hyperlipidemia & 30,879 & $10,630(34.4)$ & $20,249(65.6)$ \\
\hline Hypertension & 21,855 & $7,058(32.3)$ & $14,797(67.7)$ \\
\hline \multicolumn{4}{|l|}{ Use by ethnicity } \\
\hline Hispanic & 5,605 & $1,352(24.1)$ & $4,253(75.9)$ \\
\hline Non-Hispanica & 69,101 & $20,059(29.0)$ & $49,042(71.0)$ \\
\hline \multicolumn{4}{|l|}{ Use by race } \\
\hline White & 61,242 & 17,601 (28.7) & $43,641(71.3)$ \\
\hline Black & 6,150 & $1,650(26.8)$ & $4,500(73.2)$ \\
\hline Asian $^{\mathrm{a}}$ & 10,569 & $3,256(30.8)$ & $7,313(69.2)$ \\
\hline Other & 1,024 & $247(24.1)$ & $777(75.9)$ \\
\hline \multicolumn{4}{|c|}{ IPHR = interactive prevention health record. } \\
\hline \multicolumn{4}{|c|}{ Note: All differences between users and nonusers were statistically significant at $P<.001$. } \\
\hline
\end{tabular}

less likely to use the IPHR, on multivariate analysis race-ethnicity was a weaker predictor of use than age or having a chronic condition (Table 3). The multivariate analysis also revealed that IPHR use was less likely when clinicians were older than 55 years, younger than 35 years, or male. Interestingly, residency training status did not influence use. IPHR use was strongly associated with clinicians who identified themselves as early adopters and those who expressed comfort with IPHR use training or confidence in using the IPHR.

\section{DISCUSSION}

Small to medium-sized primary care practices can effectively engage patients to use patient portals such as the IPHR by integrating promotion into routine care. This approach appears to be more effective than mailing invitations and to match the results of more elaborate promotion efforts by large integrated health systems.

Among patients, a key factor influencing IPHR use was having a comorbid condition. Patients with chronic conditions have more office visits, laboratory and procedural tests, and selfmanagement needs. ${ }^{40,41}$ Although critics express concerns that online technologies might discriminate against older patients, ${ }^{42,43} 1$ out of 3 patients aged 60 to 69 years enrolled, the highest use

cians to notify patients about the IPHR, that sent IPHR clinical summaries to the clinician rather than medical records or nursing staff, and that did not use the IPHR to inform patients of laboratory results. Qualitative analysis of learning collaboratives identified dominant analytic findings with respect to facilitators (having a culture amenable to change and getting buy-in from all clinicians and staff), barriers (prior negative experiences with other informatics tools and competing demands on staff), and workflow (engaging staff at higher functional levels and engaging patients outside the practice). Further details are provided online in the Supplemental Appendix.

IPHR users and nonusers are compared in Table 2. Older patients were more likely to create an IPHR account-32.9\% of 60 - to 69 -year-olds enrolled-as were patients with chronic conditions $(32.5 \%$ vs $21.2 \%$, $P<.001)$. Although black and Hispanic patients were rate by any age-group.

Black and Hispanic patients were less likely to use the IPHR. Even though prior studies document a digital divide in use of personal health records among at-risk populations ${ }^{44}$ the growing ubiquity of mobile devices is closing the digital divide ${ }^{45}$ and greater use of these very technologies is being discussed to narrow health inequities. ${ }^{46-48}$

Statistically, the substantial variation in IPHR use across practices was explained largely by variation among clinicians. Patients were less likely to use the IPHR if their clinician was older, perhaps because older clinicians are less accustomed to using electronic resources in patient care. We also found lower usage rates among younger clinicians, but not among residents in particular. Why younger clinicians, most familiar with electronics, would be less inclined to promote usage is unclear. 


\section{Table 3. Multivariate Analysis of Patient and Clinician Factors That Influenced IPHR Use}

\begin{tabular}{|c|c|}
\hline Variable & $\begin{array}{c}\text { Adjusted OR } \\
(95 \% \mathrm{CI})\end{array}$ \\
\hline Patient age & $1.01(1.01-1.01)$ \\
\hline Patient sex (female vs male) & $1.09(1.03-1.15)$ \\
\hline \multicolumn{2}{|l|}{ Patient race } \\
\hline Asian vs white & $1.18(1.09-1.27)$ \\
\hline Black vs white & $0.89(0.80-0.98)$ \\
\hline Hispanic vs white & $0.36(0.18-0.73)$ \\
\hline Other vs white & $0.75(0.58-0.96)$ \\
\hline Patient's comorbidities (none vs any) & $0.67(0.63-0.71)$ \\
\hline Clinician sex (female vs male) & $1.37(1.26-1.49)$ \\
\hline \multicolumn{2}{|l|}{ Clinician age, y } \\
\hline $25-34$ vs $35-54$ & $0.72(0.66-0.80)$ \\
\hline $55+$ vs $35-54$ & $0.63(0.55-0.72)$ \\
\hline \multicolumn{2}{|l|}{ Clinician, resident status } \\
\hline Nonresident vs resident & $0.96(0.86-1.08)$ \\
\hline \multicolumn{2}{|l|}{ Clinician: early adopter ${ }^{\mathrm{a}}$} \\
\hline Agree vs disagree & $1.58(1.44-1.73)$ \\
\hline Neither vs disagree & $1.27(1.16-1.38)$ \\
\hline \multicolumn{2}{|l|}{ Clinician: training ${ }^{b}$} \\
\hline Agree vs disagree & $1.41(1.29-1.54)$ \\
\hline Neither vs disagree & $0.84(0.76-0.94)$ \\
\hline \multicolumn{2}{|l|}{ Clinician: confidence $^{c}$} \\
\hline Agree vs disagree & $1.96(1.75-2.19)$ \\
\hline Neither vs disagree & $0.83(0.75-0.92)$ \\
\hline
\end{tabular}

$\mathrm{IPHR}=$ interactive prevention health record; $\mathrm{OR}=$ odds ratio.

Notes: Values adjusted for patient and clinician characteristics, as well as practice. Only statistically significant variables were included in the final multivariate analyses.

a "Among my colleagues, I am usually one of the first to find out about a new test or treatment (strongly agree) (agree) (neither agree nor disagree) (disagree) (strongly disagree)." Reported by clinicians 1 year after fielding the IPHR.

$\mathrm{b}$ "The training I received about MyPreventiveCare was adequate (strongly agree) (agree) (neither agree nor disagree) (disagree) (strongly disagree)." Reported by clinicians 1 year after fielding the IPHR.

c "I feel confident in my ability to use MyPreventiveCare (strongly agree) (agree) (neither agree nor disagree) (disagree) (strongly disagree)." Reported by clinicians 1 year after fielding the IPHR.

Decisions made at the practice level appear to explain inflection points in uptake, underscoring the importance of system and workflow redesign. In particular, we found that uptake was influenced by the adoption of a team-based approach and the addition of a new IPHR feature to report laboratory test results. The overall uptake of the IPHR for the 8 practices masked important variances in patterns, underscoring the value to researchers of "unpacking" patterns by practice. Doing so exposed a subgroup of 2 high-achieving practices that functioned as early innovators, 3 practices that followed with a delayed uptake, and 3 practices that maintained stable but lower uptake throughout the project. Proactive reinforcement strategies throughout the study seemed critical for overall uptake.
This study has several limitations to note. First, the study lacked an internal control group. Second, the setting was restricted to a single geographic region; replication in other settings would broaden generalizability. Third, the study design permits inferences about potential disparities in care only. Future studies will need to track the influence of portal use on patient outcomes as a function of ethnicity, race, income, education, location, and patient engagement in care. Finally, we lacked data to adjust for characteristics of clinicians' patient panels, which may influence IPHR uptake independently of patient characteristics.

Despite these limitations, our data demonstrate that a substantial proportion of primary care patients will utilize online personal health records that interact with the EHR. The characteristics of these users may represent an important contextual factor for further research, especially if this class of patients is, by nature, more likely to care for themselves or access other health care services. Efforts by our study practices to promote the IPHR present another important contextual factor; uptake may be lower for online personal health records offered by Internet companies or health plans, where the imprimatur of one's personal clinician is lacking. Learning collaboratives underscored the need for practices to customize their implementation plan, which cultivates innovation. Even with such efforts, however, not all patients used the IPHR Remaining patients may require alternative engagement strategies. Nonetheless, the steady growth in uptake of this resource argues for further investigation of its capacity to promote preventive care and engage patients in self-care outside the practice.

To read or post commentaries in response to this article, see it online at http://www.annfammed.org/content/12/5/418.

Key words: personal health records; informatics; primary health care; patient-centered care; health promotion

Submitted March 2, 2014; submitted, revised, June 27, 2014; accepted July 8, 2014.

Funding support: This work was supported by the Agency for Healthcare Research and Quality (R21 HS018811) and the National Center for Advancing Translation Sciences (ULTR00058).

Acknowledgments: The authors thank the participating study practices: Fairfax Family Practice, Gainesville Family Medicine, Herndon Family Medicine, Lorton Station Family Medicine, Prince William Family Medicine, South Riding Family Medicine, Town Center Family Medicine, and Vienna Family Medicine. We thank Kristin Schmidt for project assistance and Steven Mitchell for database support.

Trial Registration Clinicaltrials.gov identifier: NCT00589173

Supplementary materials: Available at http://www.AnnFamMed. org/content/12/5/418/suppl/DC1/ 


\section{References}

1. Tang PC, Ash JS, Bates DW, Overhage JM, Sands DZ. Personal health records: definitions, benefits, and strategies for overcoming barriers to adoption. J Am Med Inform Assoc. 2006;13(2):121-126.

2. Office of the National Coordinator for Health Information Technology (ONC), Department of Health and Human Services. Health information technology: revisions to initial set of standards, implementation specifications, and certification criteria for electronic health record technology. Interim final rule with request for comments. Fed Regist. 2010;75(197):62686-62690.

3. Centers for Medicare and Medicaid Services (CMS) HHS. Medicare and Medicaid programs; electronic health record incentive program - stage 2. Final rule. Fed Regist. 2012;77(171):53967-54162.

4. Archer N, Fevrier-Thomas U, Lokker C, McKibbon KA, Straus SE. Personal health records: a scoping review. J Am Med Inform Assoc. 2011;18(4):515-522.

5. Wakefield DS, Kruse RL, Wakefield BJ, Koopman RJ, Keplinger LE, Canfield SM, Mehr DR. Consistency of Patient Preferences About a Secure Internet-Based Patient Communications Portal: Contemplating, Enrolling, and Using. American journal of medical quality: the official journal of the American College of Medical Quality. 2012;27(6):494-502.

6. Ralston JD, Coleman K, Reid RJ, Handley MR, Larson EB. Patient experience should be part of meaningful-use criteria. Health Aff (Millwood). 2010;29(4):607-613.

7. Silvestre AL, Sue VM, Allen JY. If you build it, will they come? The Kaiser Permanente model of online health care. Health Aff (Millwood). 2009;28(2):334-344.

8. Halamka JD, Mandl KD, Tang PC. Early experiences with personal health records. J Am Med Inform Assoc. 2008;15(1):1-7.

9. Ralston S, Kellett N, Williams RL, Schmitt C, North CQ. Practicebased assessment of tobacco usage in southwestern primary care patients: a Research Involving Outpatient Settings Network (RIOS Net) study. J Am Board Fam Med. 2007;20(2):174-180.

10. Roblin DW, Houston TK II, Allison JJ, Joski PJ, Becker ER. Disparities in use of a personal health record in a managed care organization. J Am Med Inform Assoc. 2009;16(5):683-689.

11. Krist $\mathrm{AH}$, Woolf $\mathrm{SH}$. A vision for patient-centered health information systems. JAMA. 2011;305(3):300-301.

12. Tang PC, Lee TH. Your doctor's office or the Internet? Two paths to personal health records. N Engl J Med. 2009;360(13):1276-1278.

13. Krist $\mathrm{AH}$, Peele $\mathrm{E}$, Woolf $\mathrm{SH}$, et al. Designing a patient-centered personal health record to promote preventive care. BMC Med Inform Decis Mak. 2011;11:73.

14. Krist AH, Woolf $\mathrm{SH}$, Rothemich SF, et al. Interactive preventive health record to enhance delivery of recommended care: a randomized trial. Ann Fam Med. 2012;10(4):312-319.

15. Krist AH, Woolf SH, Rothemich SF, et al. An Interactive Preventive Health Record to enhance delivery of recommended care: a randomized controled trial. Ann Fam Med. [Supplemental appendix.] 2012;10(4) http://www.annfammed.org/content/10/4/312/suppl/ DC1. Accessed Nov 2013.

16. US Department of Health \& Human Services. Agency for Healthcare Research and Quality. U.S. Preventive Services Task Force (USPSTF): An Introduction. http://www.ahrq.gov/clinic/uspstfix.htm. Accessed Jan 2013.

17. Krist AH. Primary care patients use interactive preventive health record integrated with electronic health record, leading to enhanced provision of preventive services. AHRQ Health Care Innovations Exchange. http://www.innovations.ahrq.gov/content. aspx?id=3743. Published December 5, 2012. Updated December 18, 2013. Accessed Jan 2013.

18. US Department of Health $\&$ Human Services. National Institutes of Health. National Heart, Lung, and Blood Institute. Complete Report: the Seventh Report of the Joint National Committee on Prevention, Detection, Evaluation, and Treatment of High Blood Pressure. Bethesda, MD: National Heart, Lung, and Blood Institute; 2004.
19. Chobanian AV, Bakris GL, Black HR, et al; National Heart, Lung, and Blood Institute Joint National Committee on Prevention, Detection, Evaluation, and Treatment of High Blood Pressure; National High Blood Pressure Education Program Coordinating Committee. The Seventh Report of the Joint National Committee on Prevention, Detection, Evaluation, and Treatment of High Blood Pressure: the JNC 7 report. JAMA. 2003;289(19):2560-2572.

20. Grundy SM, Cleeman JI, Merz CN, et al; National Heart, Lung, and Blood Institute; American College of Cardiology Foundation; American Heart Association. Implications of recent clinical trials for the National Cholesterol Education Program Adult Treatment Panel III guidelines. Circulation. 2004;110(2):227-239.

21. National Cholesterol Education Program. National Institutes of Health. National Heart, Lung, and Blood Institute. Third Report of the Expert Panel on Detection, Evaluation, and Treatment of High Blood Cholesterol in Adults. Bethesda, MD: National Heart, Lung, and Blood Institute; 2002.

22. American Diabetes Association. Standards of medical care in diabetes. Testing for pre-diabetes and diabetes in asymptomatic patients. Diabetes Care. 2008;31(suppl):S13-S14.

23. Advisory Committee on Immunization Practices. ACIP Recommendations. http://www.cdc.gov/vaccines/acip/recs/index.html Accessed Jan 2010.

24. US Department of Health and Human Services. Understanding and Improving health. In: Healthy People 2010. 2nd ed. Washington, DC: US Department of Health and Human Services; November 2000.

25. Dietary Guidelines for Americans 2010. Office of Disease Prevention and Health Promotion Web site. 2010; http://www.health.gov/ dietaryguidelines/2010.asp Published January 31, 2011. Accessed Mar 2013.

26. Glanz K, Lewis FM, Rimer B. Health Behavior and Health Education. 2nd ed. San Francisco, CA: Jossey-Bass; 1997.

27. US Department of Health \& Human Services. National Institutes of Health. National Cancer Institute. Theory at a glance: A Guide for Health Promotion Practice. 2nd ed. http://www.cancer.gov/ PDF/481f5d53-63df-41bc-bfaf-5aa48ee1da4d/TAAG3.pdf. Published September 2005. Accessed May 2009.

28. Porras JI, Robertson PJ. Organization Development Theory: A Typology and Evaluation. In: Woodman RW, Pasmore WA, eds. Research in Organizational Change and Development. Greenwich, CN: JAI Press; 1987.

29. Fischer LR, Solberg LI, Kottke TE. Quality improvement in primary care clinics. Jt Comm J Qual Improv. 1998;24(7):361-370.

30. Solberg LI. Improving medical practice: a conceptual framework. Ann Fam Med. 2007;5(3):251-256.

31. Koeck C. Time for organisational development in healthcare organisations. Improving quality for patients means changing the organisation. BMJ. 1998;317(7168):1267-1268.

32. Senge PM. The Fifth Discipline: The Art \& Practice of the Learning Organization. New York, NY: Currency Doubleday; 1990.

33. Agency for Healthcare Research and Quality. Health IT survey compendium. http://healthit.ahrq.gov/health-it-tools-and-resources/ health-it-survey-compendium. Accessed Nov 2013.

34. Venkatesh V, Morris MG, Davis GB, Davis FD. User acceptance of information techology: toward a unified view. Manage Inf Syst Q. 2003;27(3):425-478.

35. Rogers EM. Diffusion of Innovations. 5th ed. New York, NY: Free Press; 2003.

36. Davis FD. Perceived usefulness, perceived ease of use, and user acceptance of information technology. Manage Inf Syst Q. 1989; 13(3):319-340.

37. Davis FD, Bagozzi RP, Warshaw PR. User acceptance of computer technology: a comparison of two theoretical models. Manage Sci. 1989;35(8):982-1002. 
38. Crabtree BF, Miller WL. Doing Qualitative Research. 2 ed. Thousand Oaks, CA: Sage Publications; 1999.

39. Office of the National Coordinator for Health Information Technology (ONC), Department of Health and Human Services. Electronic Health Record Certification Criteria: Revision to the Definition of "Common Meaningful Use (MU) Data Set". Fed Regist. 2013;78(213):65884-65887.

40. Longo DR. Understanding health information, communication, and information seeking of patients and consumers: a comprehensive and integrated model. Health Expect. 2005;8(3):189-194.

41. Agarwal R, Anderson C, Zarate J, Ward C. If we offer it, will they accept? Factors affecting patient use intentions of personal health records and secure messaging. J Med Internet Res. 2013;15(2):e43.

42. Lober WB, Zierler B, Herbaugh A, et al. Barriers to the use of a personal health record by an elderly population. In: 2006 Annual Symposium Proceedings. Bethesda, MD: American Medical Informatics Association; 2006: 514-518.

43. Kim EH, Kim Y. Digital divide: Use of electronic personal health record by different population groups. In: 32nd Annual International Conference of the IEEE Engineering in Medicine and Biology Society. Piscataway, NJ: IEEE Engineering in Medicine and Biology Society; 2010: 1759-1762.
44. Chaudhry B, Wang J, Wu S, et al. Systematic review: impact of health information technology on quality, efficiency, and costs of medical care. Ann Intern Med. 2006;144(10):742-752.

45. Zickuhr K, Smith A. Digital Differences. http://pewinternet.org/ Reports/2012/Digital-differences/Main-Report/The-power-of-mobile. aspx. Published April 13, 2012. Accessed Jun 2012.

46. Turner-Lee N, Smedley BD, Miller J. Minorities, mobile broadband and the management of chronic diseases. Washington DC: Joint Center for Political and Economic Studies; 2012.

47. Lustria ML, Smith SA, Hinnant CC. Exploring digital divides: an examination of eHealth technology use in health information seeking, communication and personal health information management in the USA. Health Informatics J. 2011;17(3):224-243.

48. Hesse BW, Hanna C, Massett HA, Hesse NK. Outside the box: will information technology be a viable intervention to improve the quality of cancer care? J Natl Cancer Inst Monogr. 2010;2010 (40):81-89.

\section{CHANGE-OF-ADDRESS FORM \\ ANNALS OF FAMILY MEDICINE}

Please complete this form and mail to the following address or fax to Annals Circulation at 913-906-6080:

Annals of Family Medicine, Circulation Department, 11400 Tomahawk Creek Pkwy, Leawood, KS 66211-2680

Check if member of sponsoring organization:

$$
\begin{array}{ll}
\square \text { AAFP } & \square \text { ABFM } \square \text { STFM } \square \text { ADFM } \\
\square \text { AFMRD } & \square \text { NAPCRG } \square \text { CFPC }
\end{array}
$$

ID number from label on your journal cover

OLD Information (Please print.)

\begin{tabular}{ll}
\hline Name & \\
\hline Company (if applicable) & \\
\hline Address (Street plus Apt or Ste) & State \\
\hline City & Postal Code (9-digit ZIP for US) \\
\hline Country & Fax \\
\hline Telephone & \\
\hline E-Mail
\end{tabular}

NEW Information (Please print.)

\begin{tabular}{ll}
\hline Name & \\
\hline Company (if applicable) & \\
\hline Address (Street plus Apt or Ste) & \\
\hline City & Postal Code (9-digit ZIP for US) \\
\hline Country & \\
\hline Telephone & \\
\hline E-Mail & \\
\hline
\end{tabular}

